\title{
ORIGINAL
}

ARTICLES

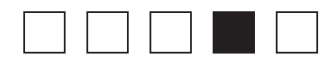

\section{Resident Remediation in Family Medicine Residency Programs: A CERA Survey of Program Directors}

Winfred Frazier, MD, MPH; Stephen A. Wilson, MD, MPH; Frank D’Amico, PhD; George R. Bergus, MD, MA-Ed

BACKGROUND AND OBJECTIVES: Identifying underperforming residents and helping them become fully competent physicians is an important faculty responsibility. The process to identify and remediate these learners varies greatly between programs. The objective of this study was to evaluate the remediation landscape in family medicine residency programs by investigating resident remediation characteristics, tools to improve the process, and remediation challenges.

METHODS: This study analyzed responses from the Council of Academic Family Medicine Educational Research Alliance (CERA) national survey of family medicine program directors in 2017. Survey questions included topics on faculty remediation training, remediation prevalence, tools for remediation, and barriers to remediation.

RESULTS: Two hundred sixty-seven of 503 program directors completed our survey (53\% response rate). Most residency programs $(245 / 264,93 \%)$ had at least one resident undergoing remediation in the last 3 years. A majority (242/265, 91\%) of residents undergoing remediation were successful within 12 months. The three most important tools to improve remediation were an accessible remediation toolkit (50\%), formal remediation recommendations from national family medicine organizations $(20 \%)$, and on-site faculty development and training (19\%). The top-two challenges to the remediation process were a lack of documented evaluations to trigger remediation and a lack of faculty knowledge and skills with effective remediation strategies.

CONCLUSIONS: Residents needing remediation are common, but most were successfully remediated within 12 months. Program directors wanted access to a standardized toolkit to help guide the remediation process.

(Fam Med. 2021;53(9):773-8.)

doi: 10.22454/FamMed.2021.546572

$\mathbf{M}$ any learners struggle at some point on their journey to become full-fledged family physicians. Family medicine residency programs (FMRPs) have the challenging task of transforming newly-minted medical school graduates into competent, independent

physicians. ${ }^{1}$ Although the vast majority of family medicine residents successfully meet the Accreditation Council of Graduate Medical Education (ACGME) competency requirements for graduation, many struggle with the six required competency areas: medical knowledge, patient care, interpersonal communication skills, practice-based learning and improvement, system-based practice, and professionalism. ${ }^{2} \mathrm{Up}$ to $9.1 \%$ of family medicine residents can be classified as residents in difficulty, or residents who fail to meet the required level of competence in one or more of the ACGME core competencies $^{3}$; their performance is below expectations. These residents need to undergo remediation to elevate their level of performance.

The remediation process is taxing on resident and faculty resources, requiring considerable time and effort in the form of increased supervision, increased communication needs, and duplication of patient care. ${ }^{4}$ Despite this increased responsibility, faculty have a duty to the resident undergoing remediation and to society to ensure the graduating resident has the skills, knowledge, and attitudes to practice safely and competently. ${ }^{5}$ Remediation is an important and necessary component of residency education. Fortunately, $77 \%-90 \%$ of residents demonstrating difficulties successfully remediate. ${ }^{3,6-9}$
From the University of Pittsburgh Medicine Center St. Margaret New Kensington Family Health Center, Family Medicine Residency Program, Kensington, PA (Drs Frazier and D'Amico); Department of Family Medicine, Boston University, Boston Medical Center (Dr Wilson); and Department of Family Medicine, Carver College of Medicine, University of Iowa, Iowa City, IA (Dr Bergus). 
Remediation can be described in three steps: (1) identification of deficiencies in a learners' performance; (2) attempt to provide remedial education to that learner; and (3) reassessment to determine the impact of that education..$^{10}$ The ACGME and American Board of Medical Specialties Milestones Project has established competency-based outcomes for residents. This focus on achieving milestones on the path to fulfilling competency-based medical education (CBME) has changed the way FMRPs evaluate residents. ${ }^{1,11,12}$

Neither the ACGME, the Association of Family Medicine Residency Directors (AFMRD), nor the Society of Teachers of Family Medicine (STFM) have established formal remediation standards or guidelines. The remediation process varies greatly across and within specialties, in part due to the inconsistencies in remediation definitions and procedures. ${ }^{13,14}$ The Clinical Competency Committee (CCC) can make recommendations to the program director on promotion, remediation, and dismissal based on the committee's consensus decision of trainee performance. The 2020 ACGME program requirements recommend documentation of any intervention to address specific deficiencies in an individual remediation plan. ${ }^{2}$ Individual programs are given considerable latitude on training faculty members regarding the process of determining resident competence.

A qualitative analysis of $34 \mathrm{CCCs}$ in California residency programs documented the need for faculty development in resident remediation procedures and training. ${ }^{15}$ Faculty proficiency in assessment, evaluation, teaching, and mentoring are critical to the ongoing success of the training program and in helping their struggling learners. It is unclear how many faculty undergo specific training in resident remediation, but generally faculty have low confidence in their ability to conduct remediation. ${ }^{16}$ As family medicine educators, it is our duty is to ensure that all our residents are given the best chance possible to satisfy the ACGME core competencies, regardless of their initial or dynamic level of competence.

The actual prevalence of family medicine residents in difficulty is poorly described in the literature. No large-scale study has assessed the prevalence of resident remediation in family medicine residency programs. This lack of information could be due to privacy concerns and the effect on program recruitment. ${ }^{3}$ However, determining the scope of family medicine residents undergoing remediation can help justify dedicated resource allocation to resident remediation and faculty training. The purpose of this study was to investigate the current state of resident remediation in FMRPs by examining remediation prevalence, variation in remediation practices, and challenges to remediation.

\section{Methods}

Ten survey questions on resident remediation were part of the larger CERA survey administered biannually to all ACGME-accredited US family medicine residency (FMR) program directors as identified by the AFMRD ( $n=526)$. The survey includes a set of invited questions proposed by family medicine faculty and selected by the CERA steering committee and recurring general questions, including FMR characteristics including residency director gender and years in position; number of nonUS graduates; whether the program was university-based or communitybased; geographic region; and community size. The survey was sent by email via SurveyMonkey, and five follow-up emails were sent to nonrespondents. Data were collected from September 2017 to October 2017.

Our 10 survey questions asked FMR program directors to retrospectively report on their residency's remediation process. The survey included questions on residency program and program director characteristics, characteristics of learners undergoing remediation, tools to improve the remediation process, and challenges to the remediation process.

We used descriptive statistics to characterize the data. We described the responses for each question using basic statistical measures (means, medians, and one-way frequency and two-way frequency distributions).

The American Academy of Family Physicians (AAFP) Institutional Review Board reviewed and approved the study.

\section{Results}

The survey was emailed to 503 program directors, with 267 responding (53.1\% overall response rate). Survey questions were optional, so the number of respondents varied per question (97.4\% answered all 10 survey questions).

\section{Survey Respondent \\ Characteristics}

Most respondents (58.4\%) were from community-based, university-affiliated programs, and most of the residency programs $(58.1 \%)$ had $25 \%$ or fewer non-US medical school graduates (Table 1). Most program directors (PDs) had been in their position 10 years or less $(78.5 \%)$.

\section{Current State of Remediation at Family Medicine Residency \\ Programs}

Ninety-three percent of responding PDs indicated that there was at least one resident in remediation during the last 3 years (Table 2). A large percentage of programs $(46 \%)$ had a $100 \%$ success rate in remediating residents over the last 3 years, which is consistent from previous smallscale studies. ${ }^{8,9,17}$ Of the six core competencies, professionalism was the most common reason for remediation (38\%), followed by medical knowledge (30\%), and patient care (19\%). Most residents requiring remediation $(86 \%)$ were identified prior to completing their first year of residency. Most residents successfully remediated within 12 months (91\%).

Most program directors $(76 \%)$ had at least some remediation training. 
Table 1: Characteristics of Family Medicine Residency Programs and Program Directors ( $\mathrm{N}=267$ )

\begin{tabular}{|c|c|c|}
\hline Program/Program Director Characteristics & $\mathbf{n}$ & $\%$ \\
\hline \multicolumn{3}{|l|}{ Type of Residency Program } \\
\hline University-based & 46 & 17.2 \\
\hline Community based, university affiliated & 156 & 58.4 \\
\hline Community based, nonaffiliated & 46 & 17.2 \\
\hline Military & 10 & 3.7 \\
\hline Other & 9 & 3.4 \\
\hline \multicolumn{3}{|l|}{ Location by Region } \\
\hline New England & 11 & 4.1 \\
\hline Middle Atlantic & 34 & 12.7 \\
\hline South Atlantic & 36 & 13.5 \\
\hline East South Central & 10 & 3.7 \\
\hline East North Central & 46 & 17.2 \\
\hline West South Central & 28 & 10.5 \\
\hline West North Central & 27 & 10.1 \\
\hline Mountain & 22 & 8.2 \\
\hline Pacific & 53 & 19.9 \\
\hline \multicolumn{3}{|l|}{ Size of Community } \\
\hline$<30,000$ & 21 & 7.9 \\
\hline $30,000-74,999$ & 45 & 17.0 \\
\hline $75,000-149,000$ & 49 & 18.5 \\
\hline $150,000-499,999$ & 69 & 26.0 \\
\hline $500,000-1$ million & 38 & 14.3 \\
\hline$>1$ million & 43 & 16.2 \\
\hline \multicolumn{3}{|l|}{ Residents From Non-US Medical Schools } \\
\hline $0 \%-24 \%$ & 154 & 58.1 \\
\hline $25 \%-49 \%$ & 44 & 16.6 \\
\hline $50 \%-74 \%$ & 33 & 12.5 \\
\hline $75 \%-100 \%$ & 33 & 12.5 \\
\hline Don't know & 1 & 0.4 \\
\hline \multicolumn{3}{|l|}{ Years Served as Program Director } \\
\hline$\leq 2$ Years & 82 & 30.8 \\
\hline 3-9 Years & 127 & 47.7 \\
\hline$\geq 10$ Years & 57 & 21.4 \\
\hline \multicolumn{3}{|l|}{ Gender of Program Director } \\
\hline Female & 111 & 41.9 \\
\hline Male & 154 & 58.1 \\
\hline \multicolumn{3}{|l|}{ Number of Residents in the Program } \\
\hline$<19$ & 98 & 36.7 \\
\hline $19-31$ & 126 & 47.2 \\
\hline$>31$ & 43 & 16.1 \\
\hline
\end{tabular}

The three most important tools to improve remediation were an accessible remediation toolkit (50\%), formal remediation recommendations from national family medicine organizations (20\%), and on-site faculty development and training (19\%, Table 3).

The main challenges to remediation were the lack of documented evaluations to trigger or guide remediation $(22 \%)$ and a lack of faculty knowledge of and skills with effective remediation strategies $(22 \%$, Table 4). Program directors identified direct observations (45\% ranked it first) and faculty evaluations (40\% ranked it first) as the top two tools to determine remediation (Figure 1).

There was no statistical difference when looking at frequency of successful remediation based on when the resident was first identified for remediation, level of $\mathrm{PD}$ remediation training, and the core competency requiring remediation (data not shown).

\section{Discussion}

Remediation in family medicine residency programs is common. Most residents remediate successfully. There will always be learners who struggle in residency, but we can improve the remediation process at any of the three steps-identify, remediate, reassess. This study shows many potential interventions to improve this process.

Professionalism is the most common reason for remediation, which is consistent with previous studies. ${ }^{3,18}$ However, in contrast to these earlier studies, program directors reported that professionalism is not necessarily the hardest competency to successfully remediate. ${ }^{19}$

A major challenge identified by $22 \%$ of respondents was a lack of documented evaluations to trigger or guide remediation (Table 4). This can be difficult because there is wide variation in faculty completion of resident evaluations. ${ }^{20}$ The $\mathrm{CCC}$ is charged to review all resident evaluations semiannually. ${ }^{2}$ 
Table 2: Summary of Survey Results

\begin{tabular}{|c|c|c|}
\hline Item & $\mathbf{n}$ & $\%$ \\
\hline \multicolumn{3}{|l|}{ ACGME Core Competency } \\
\hline Professionalism & 101 & 38 \\
\hline Medical knowledge & 79 & 30 \\
\hline Patient care & 50 & 19 \\
\hline Interpersonal and communication skills & 28 & 11 \\
\hline Practice-based learning and improvement & 6 & 2 \\
\hline Systems-based practice & 0 & 0 \\
\hline \multicolumn{3}{|c|}{ Number of Residents in Remediation } \\
\hline 0 & 19 & 7 \\
\hline $1-2$ & 97 & 37 \\
\hline $3-4$ & 90 & 34 \\
\hline $5-6$ & 37 & 14 \\
\hline$\geq 7$ & 21 & 8 \\
\hline \multicolumn{3}{|c|}{ Residents First Identified for Remediation } \\
\hline Prior to residency & 3 & 1 \\
\hline July-December PGY-1 Year & 122 & 46 \\
\hline January-June PGY-1 Year & 104 & 39 \\
\hline July-December PGY-2 Year & 28 & 10 \\
\hline January-June PGY-2 Year & 7 & 3 \\
\hline July-December PGY-3 Year & 1 & 1 \\
\hline January-June PGY-3 Year & 0 & 0 \\
\hline \multicolumn{3}{|c|}{ Frequency of Successful Remediation } \\
\hline $0 \%$ & 7 & 3 \\
\hline $1 \%-25 \%$ & 5 & 2 \\
\hline $26 \%-50 \%$ & 17 & 6 \\
\hline $51 \%-75 \%$ & 23 & 9 \\
\hline $76 \%-99 \%$ & 68 & 26 \\
\hline $100 \%$ & 122 & 46 \\
\hline N/A & 23 & 8 \\
\hline \multicolumn{3}{|l|}{ Time to Successful Remediation } \\
\hline$<6$ months & 116 & 44 \\
\hline$\geq 6$ months to $<12$ months & 126 & 47 \\
\hline$\geq 12$ months & 23 & 9 \\
\hline \multicolumn{3}{|c|}{ Amount of Program Director Remediation Training } \\
\hline Very extensive & 7 & 3 \\
\hline Substantial & 98 & 37 \\
\hline Moderate & 95 & 36 \\
\hline Limited & 48 & 18 \\
\hline None & 17 & 6 \\
\hline
\end{tabular}

Abbreviations: ACGME, Accreditation Council for Graduate Medical Education.
Practice-based learning and improvement (PBLI) and system-based practice (SBP) were the competencies least remediated. These competencies are especially difficult to measure. ${ }^{21}$ A 2017 paper identified common themes (eg, use of evidencebased medicine, care coordination) within these competencies to assist faculty in identifying deficiencies and offering remediation recommendations. $^{22}$

ACGME guidelines emphasize the importance of PDs and faculty to recognize where residents are struggling. Faculty development in early identification and effective interventions in remediation is one of the ACGME's 26 guidelines on remediation in medical education. ${ }^{23}$ Several studies have emphasized the importance of faculty development in identifying struggling residents. ${ }^{24-28}$ This study found that most PDs have some level of remediation training. However, this study identified a lack of faculty knowledge and skills with effective remediation strategies as major challenges. It is unclear how much training residency faculty have in remediation. STFM launched the Residency Faculty Fundamentals Certificate Program in June 2017. The program includes instruction on assessment and evaluation, and strategies for resident remediation. ${ }^{29}$ Remediation training is crucial to gain the ability to detect deficiencies. ${ }^{30,31}$ This is an opportunity for faculty development.

Half of the PDs think that an accessible remediation toolkit would be helpful. There are currently no specific guidelines or recommendations on resident remediation in the ACGME Program Requirements. The new ACGME guidelines state that programs should develop individualized learning plans to help correct Milestone deficiencies. ${ }^{2}$ Perhaps national family medicine organizations like AFMRD and STFM could develop a task force to develop a standardized remediation toolkit based on the core competencies and milestones. 
Table 3: Tools to Improve the Remediation Process

\begin{tabular}{|l|c|c|}
\hline \multicolumn{1}{|c|}{ Item } & n & $\%$ \\
\hline Accessible remediation toolkit & 133 & 50 \\
\hline Formal remediation recommendations & 52 & 20 \\
\hline On-site faculty development and training & 49 & 19 \\
\hline Remediation training at conferences & 20 & 7 \\
\hline Educational training in the MOC process & 10 & 4 \\
\hline
\end{tabular}

Abbreviations: MOC, maintenance of certification.

Table 4: Challenges to Remediation

\begin{tabular}{|l|c|c|}
\hline \multicolumn{1}{|c|}{ Challenge } & $\mathbf{n}$ & $\%$ \\
\hline $\begin{array}{l}\text { Lack of documented evaluations to trigger and/or guide } \\
\text { remediation }\end{array}$ & 59 & 22 \\
\hline $\begin{array}{l}\text { Lack of faculty knowledge of and skills with effective } \\
\text { remediation strategies }\end{array}$ & 59 & 22 \\
\hline Delayed implementation of remediation & 38 & 14 \\
\hline Lack of systematic process & 33 & 13 \\
\hline Lack of valid assessment tools & 32 & 12 \\
\hline $\begin{array}{l}\text { Lack of consensus on developmentally appropriate competence } \\
\text { benchmarks }\end{array}$ & 27 & 10 \\
\hline Lack of resident buy-in & 16 & 6 \\
\hline
\end{tabular}

Figure 1: Tools to Determine Remediation

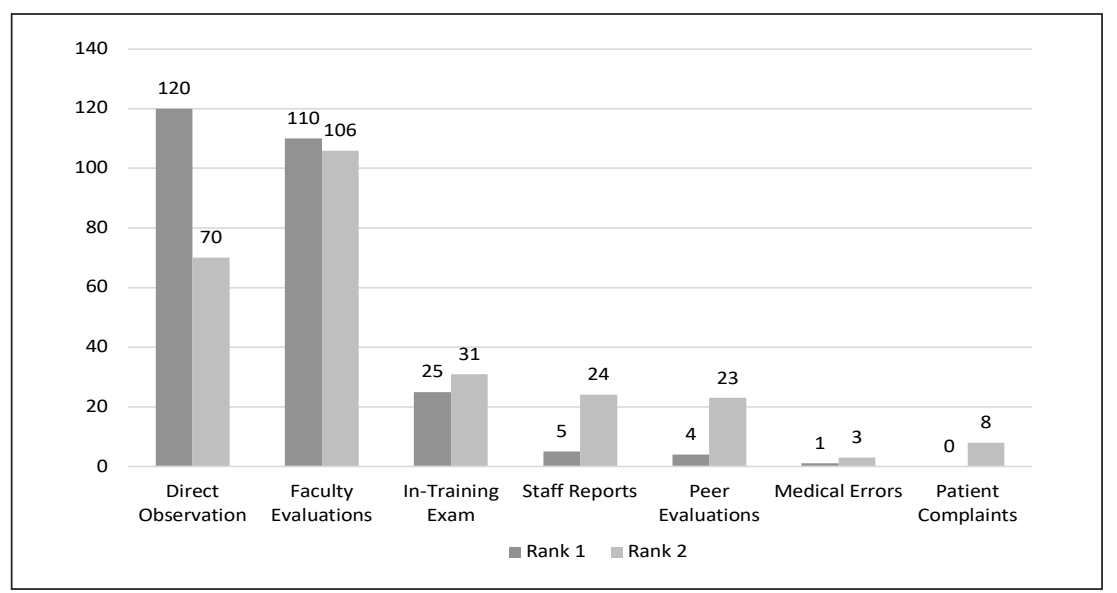

\section{Strengths}

Two hundred sixty-seven program directors provided information on remediation in their residency program. These program directors represented programs from all types of residency programs from all regions of the country.

\section{Limitations}

With a $53 \%$ response rate, it is unknown if these results are representative of FMRPs in the United
States. Survey studies are limited by selection bias and social desirability bias, which may have selected program directors who have more training in resident remediation. We asked the program directors to report on remediations undertaken during the past 3 years, but nearly one-third of the program directors had been in their position less than 3 years. As a result, the remediation data might have been incomplete. This CERA survey of program directors does not include responses from core residency faculty who are heavily involved in resident remediation, and their responses could have added important information.

\section{Future Research}

Further research into this area should include family medicine resident perspectives on remediation. This study surveyed program directors and their perceptions on the remediation process. Surveying residents on their experiences undergoing remediation, including challenges and tools for success, would likely help improve the remediation process.

Currently, no competency-based resident remediation educational toolkit exists. Further research is needed to examine faculty training in, approaches to, and feelings about working with learners who need remediation and to develop a toolbox of evidence-informed, high-yield approaches to remediation.

ACKNOWLEDGMENTS: The authors thank the CERA Steering Committee and the staff of the Society of Teachers of Family Medicine for their support and guidance in the development and execution of this survey.

CORRESPONDING AUTHOR: Address correspondence to Dr Winfred Frazier, UPMC St. Margaret Family Medicine Residency, 815 Freeport Road, Pittsburgh, PA 152153301. 412-952-0686. Fax: 412-784-5274. frazierwt2@upmc.edu.

\section{References}

1. Holmboe ES, Sherbino J, Englander R, Snell L, Frank JR; ICBME Collaborators. A call to action: the controversy of and rationale for competency-based medical education. Med Teach. 2017;39(6):574-581. doi:10.1080/01421 59X.2017.1315067

2. Accreditation Council for Graduate Medical Education. Program Requirements for Graduate Medical Education in Family Medicine. Accessed January 22, 2021. http://www.acgme.org/Portals/0/PFAssets/ProgramRequirements/120_FamilyMedicine_2020.pdf

3. Reamy BV, Harman JH. Residents in trouble: an in-depth assessment of the 25-year experience of a single family medicine residency. Fam Med. 2006;38(4):252-257.

4. Katz ED, Dahms R, Sadosty AT, Stahmer SA, Goyal D; CORD-EM Remediation Task Force. Guiding principles for resident remediation: recommendations of the CORD remediation task force. Acad Emerg Med. 2010;17(suppl 2):S95-S103. doi:10.1111/j.15532712.2010.00881.x 
5. Ellaway RH, Chou CL, Kalet AL. Situating remediation: accomodating success and failure in medical education systems. Acad Med. 2018;93(3):391-398. doi:10.1097/ ACM.0000000000001855

6. Guerrasio J, Garrity MJ, Aagaard EM. Learner deficits and academic outcomes of medical students, residents, fellows, and attending physicians referred to a remediation program, 2006-2012. Acad Med. 2014;89(2):352-358. doi:10.1097/ACM.0000000000000122

7. Zbieranowski I, Takahashi SG, Verma S, Spadafora SM. Remediation of residents in difficulty: a retrospective 10-year review of the experience of a postgraduate board of examiners. Acad Med. 2013;88(1):111-116. doi:10.1097/ ACM.0b013e3182764cb6

8. Turner JA, Fitzsimons MG, Pardo MC Jr, et al Effect of performance deficiencies on graduation and board certification rates: a 10-yr multicenter study of anesthesiology residents. Anesthesiology. 2016;125(1):221-229. doi:10.1097/ ALN.0000000000001142

9. Warburton KM, Goren E, Dine CJ. Comprehensive assessment of struggling learners referred to a graduate medical education remediation program. J Grad Med Educ. 2017;9(6):763-767. doi:10.4300/JGME-D-17-00175.1

10. Hauer KE, Ciccone A, Henzel TR, et al. Remediation of the deficiencies of physicians across the continuum from medical school to practice: a thematic review of the literature. Acad Med. 2009;84(12):1822-1832. doi:10.1097/ ACM.0b013e3181bf3170

11. Ross S, Binczyk NM, Hamza DM, et al. Association of a competency-based assessment system with identification of and support for medical residents in difficulty. JAMA Netw Open. 2018;1(7):e184581. doi:10.1001/jamanetworkopen.2018.4581

12. Pirie J, St Amant L, Glover Takahashi S. Managing residents in difficulty within CBME residency educational systems: a scoping review. BMC Med Educ. 2020;20(1):235. doi:10.1186/ s12909-020-02150-0

13. Cleland J, Leggett H, Sandars J, Costa MJ, Patel R, Moffat M. The remediation challenge: theoretical and methodological insights from a systematic review. Med Educ. 2013;47(3):242251. doi:10.1111/medu.12052
14. Rosenblatt MA, Schartel SA. Evaluation feedback and remediation in anesthesiology residency training: A survey of 124 United States programs. J Educ Perioper Med. 1999;1(2):E006

15. Hauer KE, Chesluk B, Iobst W, et al. Reviewing residents' competence: a qualitative study of the role of clinical competency committees in performance assessment. Acad Med. 2015;90(8):1084-1092. doi:10.1097/ ACM.0000000000000736

16. Dudek NL, Marks MB, Regehr G. Failure to fail: the perspectives of clinical supervisors. Acad Med. 2005;80(10)(suppl):S84-S87. doi:10.1097/00001888-200510001-00023

17. Guerrasio J, Garrity MJ, Aagaard EM. Learner deficits and academic outcomes of medical students, residents, fellows, and attending physicians referred to a remediation program, 2006-2012. Acad Med. 2014;89(2):352-358. doi:10.1097/ACM.0000000000000122

18. Svystun O, Ross S. Difficulties in residency: an examination of clinical rotations and competencies where family medicine residents most often struggle. Fam Med. 2018;50(8):613-616 doi:10.22454/FamMed.2018.794779

19. Dupras DM, Edson RS, Halvorsen AJ, Hopkins RH Jr, McDonald FS. "Problem residents": prevalence, problems and remediation in the era of core competencies. Am J Med. 2012;125(4):421-425. doi:10.1016/j.amjmed.2011.12.008

20. Blankush JM, Shah BJ, Barnett SH, et al. What are the associations between the quantity of faculty evaluations and residents' perception of quality feedback? Ann Med Surg (Lond). 2017;16:40-43. doi:10.1016/j.amsu.2017.03.001

21. Riebschleger MP, Haftel HM. Remediation in the context of the competencies: a survey of pediatrics residency program directors. J Grad Med Educ. 2013;5(1):60-63. doi:10.4300/ JGME-D-12-00024.1

22. Williamson K, Moreira M, Quattromani E, Smith JL. Remediation strategies for systemsbased practice and practice-based learning and improvement milestones. J Grad Med Educ. 2017;9(3):290-293. doi:10.4300/JGMED-16-00334.1
23. Chou CL, Kalet A, Costa MJ, Cleland J, Winston K. Guidelines: the do's, don'ts and don't knows of remediation in medical education. Perspect Med Educ. 2019;8(6):322-338. doi:10.1007/s40037-019-00544-5

24. Audétat M-C, Dory V, Nendaz M, et al. What is so difficult about managing clinical reasoning difficulties? Med Educ. 2012;46(2):216-227. doi:10.1111/j.1365-2923.2011.04151.x

25. Audétat M-C, Laurin S, Dory V. Remediation for struggling learners: putting an end to 'more of the same'. Med Educ. 2013;47(3):224-231. doi:10.1111/medu.12131

26. Audétat M-C, Voirol C, Béland N, Fernandez $\mathrm{N}$, Sanche G. Remediation plans in family medicine residency. Can Fam Physician. 2015;61(9):e425-e434.

27. Domen RE. Resident remediation, probation, and dismissal basic considerations for program directors. Am J Clin Pathol. 2014;141(6):784790. doi:10.1309/AJCPSNPAP5R5NHUS

28. Danilovich N, Kitto S, Price DW, Campbell C, Hodgson A, Hendry P. Implementing competency-based medical education in family medicine: A narrative review of current trends in assessment. Fam Med. 2021;53(1):9-22. doi:10.22454/FamMed.2021.453158

29. Theobald M. Being strategic about faculty development. Ann Fam Med. 2017;15(2):188-189. doi:10.1370/afm.2052

30. Lacasse M, Audétat MC, Boileau É, et al. Interventions for undergraduate and postgraduate medical learners with academic difficulties: A BEME systematic review: BEME Guide No. 56. Med Teach. 2019;41(9):981-1001. doi:10.1 080/0142159X.2019.1596239

31. Guerrasio J. Remediation of the struggling medical learner. Irwin, PA: Association for Hospital Medical Education; 2013. 